\title{
AnimAR: um aplicativo para criação de animações com realidade aumentada e interface tangível
}

\author{
Ricardo Filipe Reiter ${ }^{1}$, Dalton Solano dos Reis ${ }^{1}$, Mauricio Capobianco Lopes ${ }^{2}$ \\ ${ }^{1}$ Departamento de Sistemas e Computação - Universidade Regional de Blumenau \\ (FURB) - Rua Antônio da Veiga, 140 - CEP 89.030-903 - Blumenau, SC - Brasil \\ ${ }^{2}$ Programa de Pós-Graduação em Ensino de Ciências Naturais e Matemática - \\ Universidade Regional de Blumenau (FURB) - Blumenau, SC - Brasil \\ ricardof.reiter@gmail.com @gmail.com, dalton@furb.br, mclopes@furb.br
}

\begin{abstract}
Resumo. Este artigo apresenta o aplicativo AnimAR para criação de cenas animadas, utilizando Realidade Aumentada (RA) e Interfaces de Usuário Tangiveis (IUT). O aplicativo permite a criação e manipulação de cenários e objetos tridimensionais virtuais, sendo possível dar "vida" à cena ao utilizar IUT para a criação de animações dos objetos virtuais. O aplicativo foi testado com uma turma de Pedagogia. A maior dificuldade dos usuários foi na interação com a IUT, isto porque ainda há pouca familiaridade com este tipo de interface para a grande maioria das pessoas. Ainda assim, os testes realizados apontam que as funcionalidades desenvolvidas são de fácil uso, após o entendimento inicial de como a IUT funciona.
\end{abstract}

\begin{abstract}
This article introduces the AnimAR application for creating animated scenes using Augmented Reality (RA) and Tangible User Interfaces (IUT). The application allows the creation and manipulation of virtual threedimensional scenarios and objects, making it possible to "live" the scene by using IUT to create animations of virtual objects. The application was tested with a Pedagogy class. The greatest difficulty of the users was in the interaction with the IUT, because there is still little familiarity with this type of interface for the vast majority of people. Nevertheless, the tests performed indicate that the functionalities developed are easy to use, after the initial understanding of how the IUT works.
\end{abstract}

\section{Introdução}

Animações digitais e efeitos especiais estão cada vez mais presentes no cotidiano. Filmes produzidos totalmente através de computação gráfica e outros com vários efeitos especiais embutidos, já são algo rotineiro nos dias atuais e isso só tende a crescer, conforme Giorgiutti (2016, apud GIARDINA, 2016, tradução nossa), "Em Matrix foram produzidas 420 cenas de efeitos especiais. Hoje em dia, são em torno de 2000 cenas em um filme da Marvel, e eles lançam um filme por ano". Entretanto, filmes não são os únicos a utilizar de animação digital, pois os jogos eletrônicos são conhecidos pelas suas animações dinâmicas.

Segundo Brandão (2012, p. 10), "Enquanto espectador, estamos sujeitos à montagem fixa e linear dos filmes, enquanto que nos jogos eletrônicos temos controle total ou parcial sobre o ângulo e a duração dos planos imagéticos.". Neste contexto, o 
VII Congresso Brasileiro de Informática na Educação (CBIE 2018)

Anais dos Workshops do VII Congresso Brasileiro de Informática na Educação (WCBIE 2018)

que também está se tornando popular é a Realidade Aumentada. Kirner et al. (2006) definem a Realidade Aumentada (RA) como uma técnica para trazer o ambiente virtual ao ambiente físico do usuário, permitindo a interação com o mundo virtual, de maneira natural e sem necessidade de treinamento ou adaptação. Kirner et al. (2006, p. 22) também citam "Novas interfaces multimodais estão sendo desenvolvidas para facilitar a manipulação de objetos virtuais no espaço do usuário, usando as mãos ou dispositivos mais simples de interação.”, que é o caso de uma Interface de Usuário Tangível (IUT).

\begin{abstract}
[...] interfaces Tangíveis, dão forma física para informações digitais, empregando artefatos físicos como representações e controles para mídias computacionais. TUIs combinam representações físicas (por exemplo, objetos físicos manipuláveis espacialmente) com representações digitais (por exemplo, visual e áudio), produzindo sistemas interativos que são mediados pelo computador, mas geralmente não identificáveis como "computadores". (ULLMER, ISHII, 2001, p. 2, grifo do autor, tradução nossa).
\end{abstract}

Diante deste contexto, este artigo apresenta um aplicativo para a criação de animações em 3D através de uma combinação de Interface de Usuário Tangível e Realidade Aumentada. A proposta é utilizar o aplicativo como ferramenta pedagógica para auxiliar no desenvolvimento criativo das crianças ao manipular um cenário virtual e criar animações com objetos virtuais e manipular cenas (translação, rotação, escala, gravar, entre outros recursos).

\title{
2 Fundamentação Teórica
}

A seção 2.1, a seguir apresenta os conceitos básicos de Animações Digitais. A seção 2.2 apresenta sobre RA e IUT.

\subsection{Animações Digitais}

Segundo Parent (2001), animar significa literalmente "dar vida".

\begin{abstract}
Animar é mover algo (ou fazer algo parecer que move) que não pode moverse sozinho - seja ela um fantoche do King Kong, um desenho da Branca de Neve, os ponteiros de um relógio, ou uma imagem sintética de um brinquedo de cowboy de madeira. (PARENT, 2001, p. 16, tradução nossa)
\end{abstract}

Animações vêm sendo utilizadas para ensinar e entreter, desde a época dos fantoches até hoje em dia com filmes e jogos (PARENT, 2001, p. 16, tradução nossa). Parent (2001, p. 16) explica que as animações adicionam a dimensão de tempo para a computação gráfica, abrindo espaço para transmitir informação e conhecimento para o espectador, acendendo suas emoções e liberando a imaginação de criança de dentro de todos nós. Uma das técnicas utilizadas para a criação de animações é a de motion capture que, segundo Menache (2011, p. 2), é um processo na qual se grava um movimento do mundo real, coletando-se informações de pontos chaves ao longo do tempo para, no final, combiná-los em uma única representação tridimensional daquele movimento.

\subsection{Realidade Aumentada e Interface de Usuário Tangível}

Insley (2003 apud KIRNER; SISCOUTTO, 2007, p. 10) define a realidade aumentada como uma melhoria do mundo real com textos, imagens e objetos virtuais, gerados por computador. Kirner e Siscoutto (2007, p. 5) também descrevem a realidade 
VII Congresso Brasileiro de Informática na Educação (CBIE 2018)

Anais dos Workshops do VII Congresso Brasileiro de Informática na Educação (WCBIE 2018)

aumentada como a sobreposição de objetos e ambientes virtuais com o ambiente físico, unindo os dois ambientes em um só, através de algum dispositivo tecnológico.

Conforme Kirner e Siscoutto (2007, p. 5), “[...] o fato dos objetos virtuais serem trazidos para o espaço físico do usuário (por sobreposição) permitiu interações tangíveis mais fáceis e naturais, sem o uso de equipamentos especiais.". A realidade aumentada vem sendo considerada uma possibilidade de ser a próxima geração de interface popular, isto porque a realidade aumentada dispensa o uso dos equipamentos especiais, e pode ser utilizada tanto em ambientes internos quanto externos (KIRNER; SISCOUTTO, 2007, p. 5). Uma das possibilidades do uso de RA são as IUT.

As interfaces de usuário gráficas modernas fazem uma grande distinção entre os "dispositivos de entrada" e os "dispositivos de saída". Dispositivos como mouse e teclado são vistos somente como controles e dispositivos gráficos como monitores e head-mounted displays são vistos como representações visuais. As IUT exploram o conceito de espaço aberto pela eliminação desta distinção, juntando os controles e representações em uma coisa só (ULLMER; ISHII, 2001).

Ullmer e Ishii (2001) definem IUT como representações físicas para informações digitais, permitindo que objetos físicos ajam como representações e controles para um mundo virtual. Diferentemente de teclados e mouses que também são objetos físicos, as formas e posições físicas dos objetos de interfaces tangíveis desempenham um importante papel para o mundo virtual (ULLMER; ISHII, 2001).

\section{AnimAR: aplicato de RA com IUT}

O aplicativo AnimAR foi desenvolvido utilizando a engine gráfica Unity 2017.4.0f1 Personal em conjunto com o Microsoft Visual Studio Ultimate 2013 como editor de código. O Vuforia 7.0 .47 foi utilizado como framework de realidade aumentada e já vem embutido com as versões mais recentes do Unity, que é o caso da utilizada para desenvolver este projeto. Para a criação dos marcadores, foi utilizada a ferramenta AR Marker Generator by Brosvision, que gera imagens aleatórias e otimizadas para reconhecimento de marcadores RA, em conjunto com a ferramenta Adobe Photoshop CS6 para edição das mesmas.

Para os marcadores do AnimAR, as imagens foram geradas pela ferramenta geradora de marcadores e, então, editadas no Adobe Photoshop CS6. No Photoshop as imagens foram cortadas, transformadas em tons de cinza e adicionadas informações relevantes para o usuário para a identificação dos marcadores, como o nome do marcador.

O Animar conta com 11 imagens, sendo cinco imagens simples de uma face e seis imagens para as seis faces do marcador cubo. Levando em consideração que o usuário utilizará a aplicação a uma distância média aproximada de 50 centímetros, os marcadores foram dimensionados a possuírem no mínimo cinco centímetros de altura e largura. O marcador cubo (Figura 1), que segue as mesmas regras das imagens simples, porém com seis faces, foi dimensionado no tamanho $5 \times 5 \times 5$ centímetros. Os marcadores seletor e gravador (Figura 2), possuem 17 centímetros de largura e 6,5 de altura. Os marcadores inspetor e lixeira (Figura 3), possuem 6x6 centímetros de dimensão. Por fim, o marcador cena (Figura 3), possui o tamanho de 15x15 centímetros. 
VII Congresso Brasileiro de Informática na Educação (CBIE 2018)

Anais dos Workshops do VII Congresso Brasileiro de Informática na Educação (WCBIE 2018)

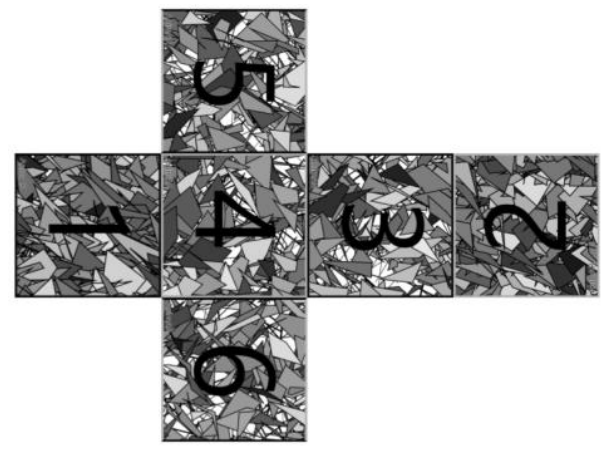

Figura 1 - Imagem utilizada para o marcador Seletor e para o cubo
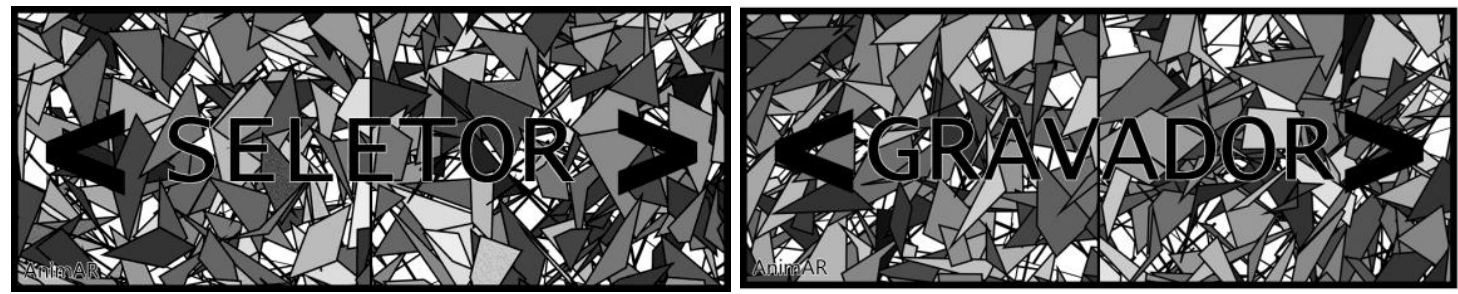

Figura 2 - Marcadores seletor e gravador
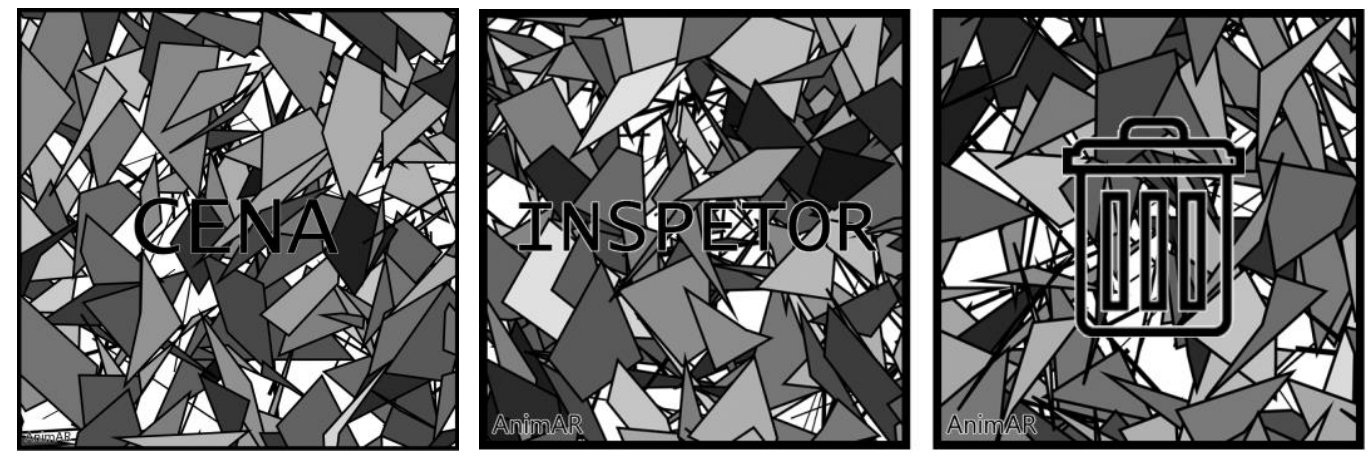

Figura 3 - Marcadores cena, inspetor e lixeira

Para a utilização do aplicativo, é necessário possuir em mãos o kit de marcadores da aplicação e um dispositivo móvel com o aplicativo instalado. O Menu Inicial é apresentado na Figura 4. Ao clicar no botão Iniciar é aberta a visualização da câmera do dispositivo para começar a identificar os marcadores.

\section{AnimAR}

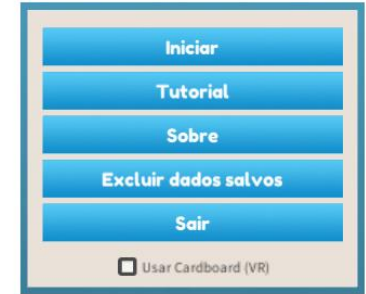

Figura 4 - Menu inicial da aplicação 
VII Congresso Brasileiro de Informática na Educação (CBIE 2018)

Anais dos Workshops do VII Congresso Brasileiro de Informática na Educação (WCBIE 2018)

Com a visão da câmera ativa, é possível apontar a câmera para os marcadores e começar a utilizar a aplicação. Apontando a câmera para o marcador Cena, o usuário consegue visualizar a representação gráfica da cena atual, conforme a Figura 5.

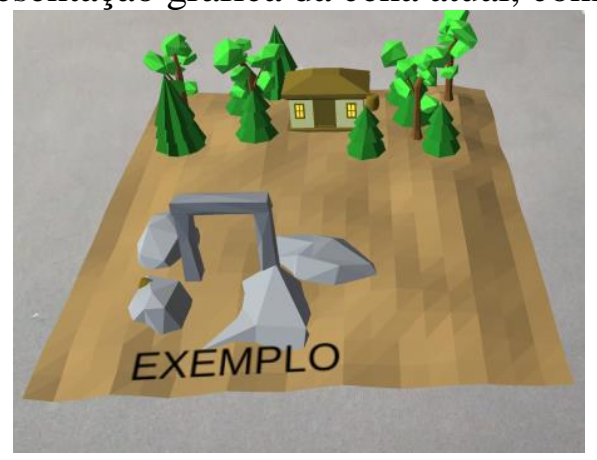

Figura 5 - Marcador Cena, visto pela visão da câmera

Apontando a câmera para o marcador Seletor, o usuário visualiza um menu de seleção, que cria uma interface tangível para a interação com o usuário. A Figura 6 mostra o marcador Seletor, com o seletor no modo Fábrica de Objetos. Pressionando < ou >, o usuário navegará entre os objetos do seletor atual. Ao pressionar o botão de troca de seletor, o usuário pode selecionar entre os seletores de Fábrica de Objetos, Seleção de Animação e Seleção de Cena.

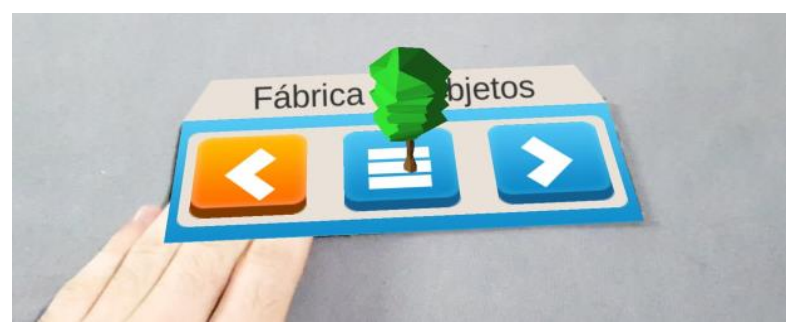

Figura 6 - Marcador Seletor no modo Fábrica de Objetos

No Seletor de Cena, ao pressionar < ou > a cena atual no marcador Cena é trocada para a cena selecionada. Quando pressionado > e não houver mais cenas seguintes, uma nova cena em branco é criada.

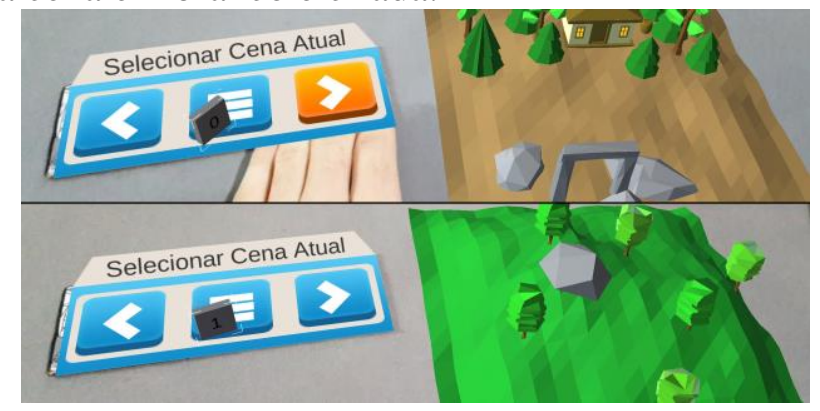

Figura 7 - Mudando a cena atual

Utilizando o marcador Cubo, o usuário pode mover o objeto selecionado na Fábrica de Objetos para a cena, adicionando-o na mesma. Para selecionar com o Cubo, o usuário deve manter o indicador do cubo apontado para o objeto e aguardar dois segundos imóvel para que o objeto seja selecionado pelo cubo. Esse mesmo processo deve ser feito para adicionar o objeto em uma determinada posição da cena. O indicador 
VII Congresso Brasileiro de Informática na Educação (CBIE 2018)

Anais dos Workshops do VII Congresso Brasileiro de Informática na Educação (WCBIE 2018)

do cubo fica amarelo e o objeto que está sendo selecionado fica realçado em vermelho, como forma de auxílio ao usuário. A Figura 8 mostra o usuário selecionando um objeto da Fábrica de Objetos do marcador Seletor, com o marcador Cubo, e adicionando na cena atual no marcador Cena.

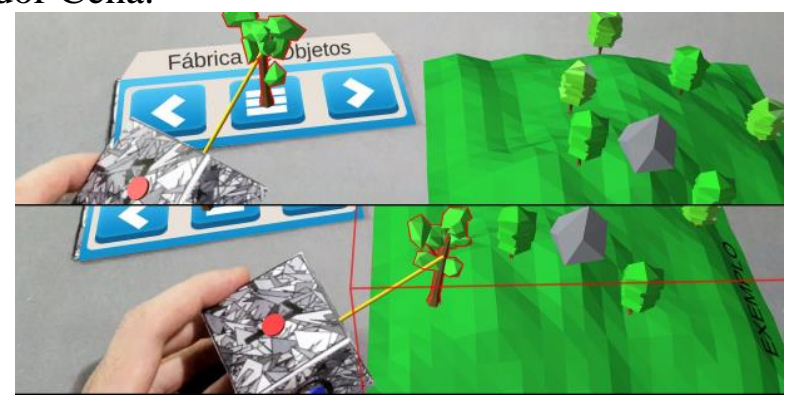

Figura 8 - Adicionando um novo objeto na cena

Ao apontar a câmera para o marcador Gravador, o menu de interface tangível de gravação é apresentado ao usuário com três botões (Figura 9). O primeiro botão retorna todas as animações para o início (no caso para o tempo zero da animação). O segundo é para iniciar a gravação de uma nova animação. O último, o botão de play e pause, executa ou para todas as animações da cena. A interface apresenta também uma linha do tempo das animações, mostrando onde cada animação acaba e qual o tempo atual e final, em segundos, da execução das animações.

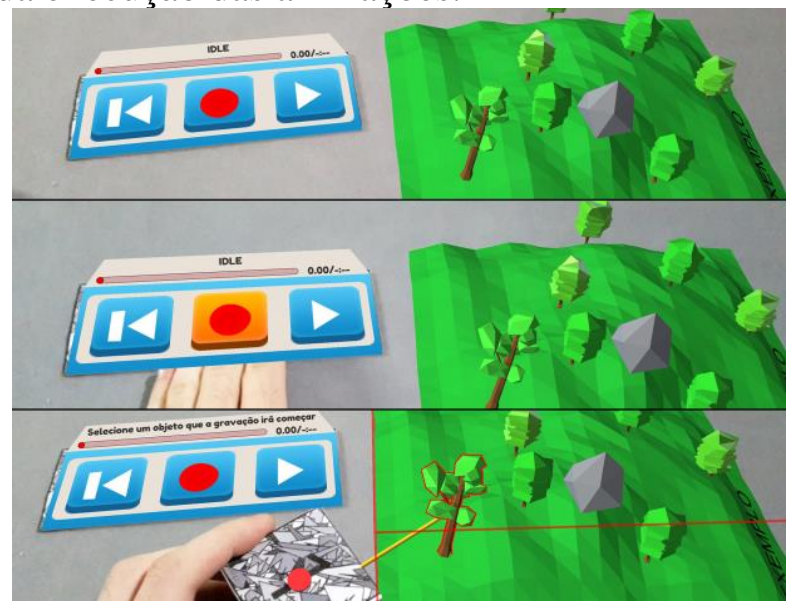

Figura 9 - Adicionando um novo objeto na cena

Ao pressionar o botão de gravação, o gravador entra em estado de espera até que o usuário selecione o objeto da cena na qual deseja gravar uma animação. Quando selecionado, a gravação começa e, a partir deste momento, é gravada a movimentação do objeto para gerar a animação. A gravação para quando o marcador Cubo é perdido ou escondido da visão da câmera ou quando pressionado o botão de gravar novamente.

Apontando a câmera para o marcador Inspetor, em conjunto com o marcador Cena ou Seletor, o usuário pode inspecionar os objetos para extrair informações relevantes. Na Figura 10, o usuário aponta o Inspetor para um objeto da cena, mostrando que o mesmo possui a animação de número dois da cena com a duração de oito segundos, em seguida, apontando para o ícone da animação no marcador Seletor, visualiza o tempo de duração da primeira animação. 
VII Congresso Brasileiro de Informática na Educação (CBIE 2018)

Anais dos Workshops do VII Congresso Brasileiro de Informática na Educação (WCBIE 2018)

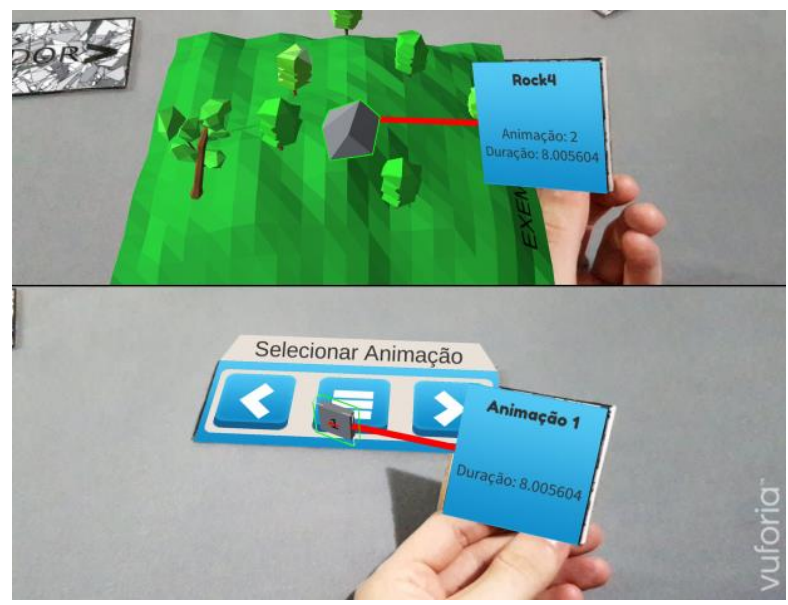

Figura 10 - Marcador Inspetor inspecionando objetos da Cena e do Seletor

Por fim, com a utilização do marcador Lixeira, o usuário pode mover objetos da cena, ícones de animações e ícones de cenas para a lixeira, excluindo-os. Caso o usuário mova um ícone de animação para a lixeira, a animação respectiva será excluída. Caso mova um ícone de cena, a cena selecionada será também excluída. A Figura 11 mostra o usuário movendo um objeto da cena para a lixeira.

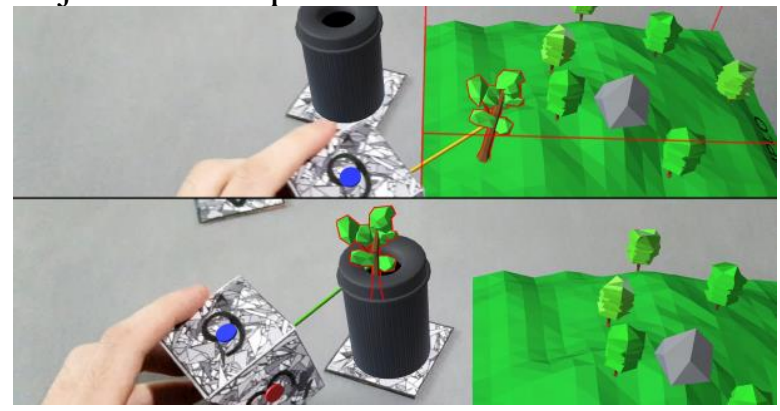

Figura 11 - Movendo objetos para a lixeira

Para voltar ao Menu Principal, o usuário deve pressionar o botão de voltar do dispositivo móvel que está sendo utilizado.

\subsection{ANÁLISE DOS RESULTADOS}

Os testes foram realizados no mês de junho de 2018, no laboratório LIFE do campus 1 da Universidade Regional de Blumenau, com uma turma do curso de Pedagogia. A turma foi dividida em oito ilhas, cada uma contendo um dispositivo tablet ou smartphone, um notebook com um formulário de pesquisa Google Forms aberto e um kit de marcadores. Cada ilha teve aproximadamente 30 minutos para utilizar a aplicação e responder o formulário em conjunto, possuindo em média três alunos por ilha. Inicialmente, foi realizada uma apresentação sobre as funcionalidades básicas do aplicativo e, em seguida, os estudantes começaram a realização dos testes através do formulário de testes, em formato de passo a passo, para responderem um questionário de avaliação no final. A turma foi dividida em oito grupos, porém foram recebidas somente sete submissões do formulário, pois um grupo não conseguiu responder a tempo. A primeira etapa do formulário consiste em recolher dados sobre o perfil dos usuários, cujas respostas estão disponibilizadas na Tabela 1. 
VII Congresso Brasileiro de Informática na Educação (CBIE 2018)

Anais dos Workshops do VII Congresso Brasileiro de Informática na Educação (WCBIE 2018)

\begin{tabular}{|c|c|}
\hline Idade & $14,3 \% 20$ anos - $28,6 \% 21$ anos - 42,9\% 22 anos - \\
& $14,3 \% 27$ anos \\
\hline Sexo & $100 \%$ Feminino \\
\hline Utiliza dispositivos móveis com qual frequência & $85,7 \%$ Frequentemente \\
& $14,3 \%$ Ãs vezes \\
\hline Já utilizou aplicações de Realidade Aumentada & $57,1 \%$ Sim \\
& $42,9 \%$ Não \\
\hline Já utilizou aplicações de Realidade Virtual & $71,4 \%$ Sim \\
& $28,6 \%$ Não \\
\hline
\end{tabular}

Tabela 1 - Perfil dos usuários

Conforme observado, a maior parte das estudantes possuía entre 20 e 22 anos de idade, sendo todos do sexo feminino. Grande parte já utilizava dispositivos móveis com bastante frequência, e já tinham experienciado aplicações de Realidade Virtual, porém, somente pouco mais da metade já tinha utilizado aplicações de Realidade Aumentada.

A segunda etapa do formulário é um passo a passo que demonstra todas as funcionalidades básicas da aplicação, como criar cenas, adicionar objetos e gravar animações. Para cada passo, as estudantes deveriam informar se conseguiram realizar o passo com sucesso ou não. Os resultados estão disponíveis na Tabela 2.

\begin{tabular}{|c|c|}
\hline $\begin{array}{c}\text { Abra o aplicativo AnimAR e realize o pequeno tutorial dentro dele. O objetivo é } \\
\text { aprender os comandos básicos. }\end{array}$ & 100\% Concluído \\
\hline $\begin{array}{l}\text { Aperte "Iniciar" no menu principal para iniciar o jogo. Utilize os marcadores } \\
\text { "Cena" e "Seletor", tente fazer com que a câmera do dispositivo detecte-os. }\end{array}$ & 100\% Concluído \\
\hline $\begin{array}{l}\text { O modo padrão do marcador "Seletor" é o Fábrica de Objetos. Aperte o botão do } \\
\text { meio para trocar o seletor, até chegar no modo seletor de cena. }\end{array}$ & 100\% Concluído \\
\hline $\begin{array}{l}\text { No modo "Seletor de Cena", você pode navegar entre as cenas da sua aplicação. } \\
\text { Experimente navegar entre as cenas com os botões "<" e ">", visualizando a cena } \\
\text { no marcador "Cena". Por padrão, o aplicativo vem com duas cenas de exemplo. }\end{array}$ & $\begin{array}{l}71,4 \% \text { Concluído } \\
28,6 \% \text { Não } \\
\text { conseguiu concluir }\end{array}$ \\
\hline $\begin{array}{l}\text { Mude a cena atual para a Cena } 0 . \text { Mude o seletor atual para a "Fábrica de Objetos". } \\
\text { Navegue entre a fábrica até encontrar uma pedra cinza. Com o marcador "Cubo", } \\
\text { tente mover esse objeto da fábrica para dentro da Cena 0, em qualquer lugar da } \\
\text { cena. Para selecionar o objeto antes de mover, você deve deixar o raio indicador do } \\
\text { cubo dentro do objeto, parado por alguns segundos. } \\
\end{array}$ & $100 \%$ Concluído \\
\hline $\begin{array}{l}\text { Agora, pegue o marcador "Gravador". Pressione o botão do meio para iniciar uma } \\
\text { gravação. Com o marcador "Cubo", selecione a pedra anteriormente adicionada à } \\
\text { cena. Ao selecionar a pedra a gravação iniciará automaticamente. Movimente a } \\
\text { pedra pela cena, de acordo como você deseja animá-la. Quando você terminar sua } \\
\text { animação, aperte novamente o botão de gravar para parar a gravação, ou } \\
\text { tampe/esconde o marcador "Cubo" para que ele não seja mais detectado e pare a } \\
\text { gravação. }\end{array}$ & $\begin{array}{l}85,7 \% \text { Concluído } \\
14,3 \% \text { Não } \\
\text { conseguiu concluir }\end{array}$ \\
\hline $\begin{array}{l}\text { Pressione o botão de "Play" para então reproduzir a animação anteriormente } \\
\text { gravada. Pronto, você produziu a sua primeira animação! Experimente gravar } \\
\text { novas animações para outros objetos da mesma cena. }\end{array}$ & $\begin{array}{l}85,7 \% \text { Concluído } \\
14,3 \% \text { Não } \\
\text { conseguiu concluir }\end{array}$ \\
\hline $\begin{array}{l}\text { Pegue o marcador "Inspetor", plugue então inspetor no objeto que você acabou de } \\
\text { animar, e verifique se aparecem informações sobre aquele objeto e sua animação. }\end{array}$ & $100 \%$ Concluído \\
\hline $\begin{array}{c}\text { Pegue agora o marcador "Seletor" e mude o modo para o "Seletor de Animações". } \\
\text { Verifique que agora a animação deve possuir a animação 0. Com o "Seletor de } \\
\text { Animações" e o marcador de "Cena" abertos ao mesmo tempo, você pode } \\
\text { visualizar na cena qual o objeto animado pela animação atual selecionada no } \\
\text { seletor, sendo o objeto contornado em azul. }\end{array}$ & 100\% Concluído \\
\hline $\begin{array}{l}\text { Ative o marcador "Lixeira". Com o "Seletor de Animações" ainda aberto, pegue o } \\
\text { marcador "Cubo" e tente mover o ícone da animação "0" para a lixeira. A animação } \\
\text { então deverá ser excluída. Tente pressionar "Play" no marcador "Gravador", e } \\
\text { verifique se a animação não está mais presente. }\end{array}$ & $\begin{array}{l}85,7 \% \text { Concluído } \\
14,3 \% \text { Não } \\
\text { conseguiu concluir }\end{array}$ \\
\hline
\end{tabular}

Tabela 2 - Passo a passo das funcionalidades básicas 
VII Congresso Brasileiro de Informática na Educação (CBIE 2018)

Anais dos Workshops do VII Congresso Brasileiro de Informática na Educação (WCBIE 2018)

Conforme observado, em grande parte os objetivos conseguiram ser concluídos com facilidade, com exceção do quarto passo, onde $28,7 \%$ dos alunos tiveram dificuldades. Observou-se ser mais difícil pois é o primeiro passo em que há uma interação mais profunda com a interface tangível, sendo necessário observar dois marcadores simultaneamente, o de seletor e o de cena. Observou-se também, um certo desentendimento de como o seletor funciona e os três tipos diferentes de seleção. Também para gravar a animação muitos estudantes tiveram dificuldade em entender, como quando se aperta o gravar e deve então selecionar um objeto para começar a gravar. Muitas vezes, o botão de gravar era pressionado duas vezes, anulando o início da gravação. Apesar de o marcador de gravação dar um feedback textual sobre o início da gravação, as estudantes não conseguiram notar este tipo de feedback.

A penúltima etapa do formulário de testes, consistia em trabalhar a parte criativa de construção com a aplicação, incentivando-as a adicionarem objetos e animações de acordo com a vontade deles. Nesta etapa, grande parte já tinha conseguido entender como a aplicação funciona, porém, uma parte dos grupos não conseguiu concluir a tempo. Os resultados podem ser observados na Tabela 3.

\begin{tabular}{|c|c|}
\hline Com o "Seletor de Cenas", navegue até a Cena 2, que é uma cena & $71,4 \%$ Concluído \\
completamente nova. Agora, fazendo uso dos marcadores ensinados, construa \\
uma cena que contenha dois portais de pedra, um em cada extremidade do \\
mapa. Crie uma "rua" entre esses dois portais, com árvores, pedras e outros \\
conseguiu concluir \\
objetos pelo caminho. No final, adicione um Lobo em um dos portais de pedra, \\
e anime-o fazendo com que ele "ande" de um portal para o outro. \\
\hline $\begin{array}{c}\text { Se desejar, fique a vontade de criar novas animações para esta cena. Você pode } \\
\text { por exemplo, adicionar novos lobos na cena e fazer uma matilha de lobos } \\
\text { passeando pelo bosque. }\end{array}$ \\
$\begin{array}{c}71,4 \% \text { Concluído } \\
\text { conseguiu concluir }\end{array}$ \\
\hline
\end{tabular}

\section{Tabela 3 - Modo livre}

Por fim, a última etapa consistia em uma avaliação geral do uso da ferramenta, avaliando diferentes critérios de usabilidade com notas de zero à cinco. Os resultados desta etapa, estão disponíveis na Tabela 4.

\begin{tabular}{|c|c|c|c|c|c|}
\hline $\begin{array}{c}\text { Os passos desta pesquisa foram concluídos com } \\
\text { facilidade? }\end{array}$ & & $\begin{array}{c}14,3 \% \\
-2\end{array}$ & $\begin{array}{c}71,4 \% \\
-3\end{array}$ & $\begin{array}{c}14,3 \% \\
-4\end{array}$ & \\
\hline $\begin{array}{c}\text { Quantas tarefas você concluiu sem NENHUM auxílio } \\
\text { externo? }\end{array}$ & & $\begin{array}{l}14,3 \% \\
-2\end{array}$ & $\begin{array}{l}42,9 \% \\
-3\end{array}$ & $\begin{array}{l}28,6 \% \\
-4\end{array}$ & $\begin{array}{c}14,3 \% \\
-5\end{array}$ \\
\hline $\begin{array}{c}\text { Como você classifica a usabilidade de se construir } \\
\text { novas cenas/cenários? }\end{array}$ & $\begin{array}{c}14,3 \% \\
-1\end{array}$ & $\begin{array}{l}14,3 \% \\
-2\end{array}$ & & $\begin{array}{c}57,1 \% \\
-4\end{array}$ & $\begin{array}{l}14,3 \% \\
-5\end{array}$ \\
\hline $\begin{array}{l}\text { Como você classifica a usabilidade de se gravar } \\
\text { animações? }\end{array}$ & & $\begin{array}{c}42,9 \% \\
-2\end{array}$ & $\begin{array}{c}28,6 \% \\
-3\end{array}$ & $\begin{array}{c}14,3 \% \\
-4\end{array}$ & $\begin{array}{l}14,3 \% \\
-5\end{array}$ \\
\hline $\begin{array}{l}\text { Como você classifica a usabilidade do AnimAR em } \\
\text { Geral? }\end{array}$ & & $\begin{array}{l}14,3 \% \\
-2\end{array}$ & $\begin{array}{c}14,3 \% \\
-3\end{array}$ & $\begin{array}{c}42,9 \% \\
-4\end{array}$ & $\begin{array}{l}28,6 \% \\
-5\end{array}$ \\
\hline $\begin{array}{l}\text { Você acha que o AnimAR cumpriu seu objetivo de } \\
\text { experimentar e fornecer uma nova maneira de se criar } \\
\text { animações com facilidade? }\end{array}$ & & $\begin{array}{c}14,3 \% \\
-2\end{array}$ & $\begin{array}{c}28,6 \% \\
-3\end{array}$ & $\begin{array}{c}28,6 \% \\
-4\end{array}$ & $\begin{array}{c}28,6 \% \\
-5\end{array}$ \\
\hline
\end{tabular}

\section{Tabela 4 - Avaliação Geral}

A maioria dos grupos acharam que somente metade dos passos foram fáceis, entretanto, $50 \%$ dos grupos conseguiram concluir ao menos metade das tarefas sem auxílio externo e 37,5\% conseguiram concluir todas ou quase todas as tarefas sem auxílio. A maioria achou fácil a construção de cenários, porém já ao gravar animações, a maioria achou ruim e difícil. A parte de gravar animações foi onde se observou maior dificuldade e necessidade de auxílio do autor e do orientador, observou-se 
desentendimento em como a parte de gravar e parar funciona, ficando claro que esta parte da ferramenta não ficou de fácil entendimento e usabilidade para usuários que não estão acostumados com este tipo de aplicação. Entretanto, as avaliações da usabilidade em geral da ferramenta foram satisfatórias, sendo que 71,5\% dos grupos concluíram que a aplicação possuí uma usabilidade boa ou ótima.

\section{Conclusões}

Este trabalho mostrou o desenvolvimento de um aplicativo para a criação de cenários animados, utilizando Realidade Aumentada e Interfaces Tangíveis, em que objetos do mundo real interagem com objetos virtuais, permitindo o usuário utilizá-los para manipular o cenário virtual. O objetivo de disponibilizar uma nova maneira de se criar animações, junto com seus objetivos específicos, foram atingidos e comprovados com a realização dos testes

Os testes foram realizados com um grupo pequeno de alunos, mas apesar disso foi possível obter resultados satisfatórios. Os alunos mostraram-se interessados no funcionamento da aplicação, conseguindo realizar os objetivos propostos ainda que com alguma dificuldade. A RA juntamente com a IUT, possibilitaram a criação de cenários e animações, permitindo um novo nível de interação do usuário com a ferramenta. Este tipo de interação, evidenciou-se ser mais fácil para usuários não técnicos, que não possuem conhecimento de ferramentas de modelagem 3D e animação, a criarem mundos virtuais e dar vida aos mesmos através de pequenas animações. A contribuição social deixada por este trabalho se dá pela possibilidade da utilização da ferramenta na área da Pedagogia, podendo ser trabalhada a criatividade em sala de aula, ajudando no desenvolvimento das crianças.

\section{Referências}

BRANDÃO, Luis R. G. Jogos Cinematográficos ou Filmes Interativos? A semiótica e a interatividade da linguagem cinematográfica nos jogos eletrônicos. In: Simpósio Brasileiro de Jogos e Entretenimento Digital, 11., 2012, Brasília. Anais... Brasília: Centro de Convenções Ulysses Guimarães, 2012. p. 165-174.

GIARDINA, Carolyn. As the Demand for Visual Effects Grows, a Shortage of Artists Looms Ahead. [S.1.], 2016. Disponível em:

$<$ http://www.hollywoodreporter.com/behind-screen/as-demand-visual-effects-grows888415>. Acesso em: 07 set. 2017.

KIRNER, Claudio et al. Fundamentos e Tecnologia de Realidade Virtual e Aumentada. Belém, PA: [s.n.], 2006.

KIRNER, Claudio; SISCOUTTO, Robson. Realidade Virtual e Aumentada: Conceitos, Projeto e Aplicações. Petrópolis, RJ: [s.n.], 2007.

MENACHE, Alberto. Understanding Motion Capture for Computer Animation. Burlington, Massachusetts, Morgan Kaufmann Publishers, 2011.

PARENT, Rick. Computer Animation: Algorithms and Techniques. San Francisco, Morgan Kaufmann Publishers, 2001.

ULLMER, Brygg.; ISHII, Hiroshi. Emerging frameworks for tangible user interfaces. In: CARROL, John M. (Ed.). Human-Computer Interaction in the New Millenium. Ann Arbor, MI, U.S.A: University of Michigan. Ann Arbor, 2001. p. 579-601. 